\title{
Suppression of autophagy facilitates hydrogen gas-mediated lung cancer cell apoptosis
}

\author{
LEYUAN LIU, ZHENFENG YAN, YUANYUAN WANG, JINGHONG MENG and GANG CHEN
}

\begin{abstract}
Department of Respiration, The Third Hospital of Hebei Medical University, Shijiazhuang, Hebei 050051, P.R. China
\end{abstract}
Received January 20, 2020; Accepted July 7, 2020

DOI: $10.3892 / \mathrm{ol} .2020 .11973$

\begin{abstract}
Our previous study found that hydrogen gas $\left(\mathrm{H}_{2}\right)$ could efficiently inhibit lung cancer progression; however, the underlying mechanisms still remains to be elucidated. The present study aimed to explore the roles of $\mathrm{H}_{2}$ in lung cancer cell autophagy, and reveal the effects of autophagy on $\mathrm{H}_{2}$-mediated lung cancer cell apoptosis and the underlying mechanisms. The expression levels of proteins associated with cell apoptosis and autophagy were detected using western blot analysis. Cell autophagy was inhibited by 3-methyladenine treatment or Beclin1 downregulation, while rapamycin was used to induce autophagy. Cell growth and apoptosis were detected using the Cell Counting Kit-8 and flow cytometry assays, respectively. The results demonstrated that cell apoptosis and autophagy were significantly enhanced in the A549 and $\mathrm{H} 1975$ lung cancer cell lines treated with $\mathrm{H}_{2}$. However, autophagy enhancement weakened $\mathrm{H}_{2}$ roles in promoting cell apoptosis and vice versa. In addition, it was found that $\mathrm{H}_{2}$ treatment induced marked decreases in the protein expression levels of phosphorylated STAT3 and Bcl2, and overexpression of STAT3 abolished $\mathrm{H}_{2}$ roles in promoting cell apoptosis and autophagy. Overall, the present study revealed that $\mathrm{H}_{2}$ can promote lung cancer cell apoptosis and autophagy via inhibiting the activation of STAT3/Bcl2 signaling and suppression of autophagy can enhance $\mathrm{H}_{2}$ roles in promoting lung cancer cell apoptosis.
\end{abstract}

\section{Introduction}

Hydrogen gas $\left(\mathrm{H}_{2}\right)$, as a type of endogenous gas, has been demonstrated to not only serve as a crucial energy source, but also to exert crucial roles in physiological regulation (1). Hydrogen molecules can enter tissues and exert anti-inflammatory, antioxidant and anti-apoptotic roles (2).

Correspondence to: Dr Gang Chen, Department of Respiration, The Third Hospital of Hebei Medical University, 139 Ziqiang Road, Shijiazhuang, Hebei 050051, P.R. China

E-mail: chengang098123@163.com

Key words: hydrogen gas, cell apoptosis, cell autophagy, STAT/Bcl2 signaling
Notably, $\mathrm{H}_{2}$ shows high safety and efficacy to patients in a clinical setting (3). Intravenous administration of $500 \mathrm{ml} \mathrm{H}_{2}$ significantly improved the erythema and associated symptoms in 4 patients with acute erythematous skin diseases, with no changes in the physiological parameters, such as body temperature, blood pressure and pulse rate, or deterioration of liver and kidney function. In addition, two volunteers (one for intravenous $\mathrm{H}_{2}$ administration and the other for $\mathrm{H}_{2}$ inhalation) demonstrated no discomfort (3). Recently, $\mathrm{H}_{2}$ has been also applied in a clinical setting to improve the hearing loss induced by radiotherapy in patients with nasopharyngeal cancer (ClinicalTrials.gov identifier, NCT03818347) (4). In that study, $\mathrm{H}_{2}$ (67\% hydrogen and $33 \%$ oxygen) was generated using the hydrogen-oxygen nebulizer through the electrolysis of water and the results demonstrated that hydrogen-oxygen therapy could markedly improve binaural hearing (4). Another Phase 1 trial (ClinicalTrials.gov identifier, NCT04046211) aims to explore the safety of $\mathrm{H}_{2}$ on healthy adult volunteers. In the study, 8 volunteers were included, 2 of which were exposed to $2.4 \% \mathrm{H}_{2}$ in medical air for $24 \mathrm{~h}, 2$ who were exposed to the same gas for $48 \mathrm{~h}$ and the other 4 patients exposed to the same gas for $72 \mathrm{~h}$ (https:/clinicaltrials. gov/ct2/show/NCT04046211). In addition, Dole et al (5) proposed in 1975 , for the first time, that $\mathrm{H}_{2}$ has anti-cancer potential. Similarly, our research group previously found that $\mathrm{H}_{2}$ administration significantly represses cell growth, migration and invasion capacities and induced cell apoptosis in lung cancer A549 and H1975 cells (6). However, the molecular mechanisms remain largely unknown.

Autophagy and apoptosis are indispensable biological processes and serve crucial roles in individual development (7). Autophagy, also known as macroautophagy, is a 'self-eating' process, which engulfs cytoplasmic proteins, complexes or organelles into the autophagosome (a cytoplasmic double membrane structure), leading to degradation and recycling (8). Autophagy is modulated by autophagy-related genes (ATGs) through two evolutionarily conserved ubiquitin-like conjugation systems, known as the ATG12-ATG5 and the ATG8 light chain 3 (LC3)-phosphatidylethanolamine (PE) systems. Microtubule-associated protein 1A/1B LC3BI is conjugated with PE to become LC3BII, which associates with the outer and inner membranes of the autophagosome (9). It is known that autophagy maintains cellular homeostasis and protects against various diseases, including cancer (10-12). However, its role in carcinogenesis is controversial. Accumulating evidence 
has found that autophagy to be a 'double-edge sword' in the progression of cancer $(13,14)$.

Signal transducer and activator of transcription (STAT) 3 is a latent transcription factor which modulates extracellular signals by interacting with polypeptide receptors (15). STAT3 protein becomes transcriptionally activated primarily through tyrosine phosphorylation, which then dimerizes, translocates to the nucleus and binds to sequence-specific DNA elements, leading to the transcription of target genes (16). STAT3 has been found to serve as an oncogene and frequently hyper-activated in a number of types of cancer, including lung cancer, contributing to cancer cell survival, proliferation, metastasis and angiogenesis $(17,18)$. In addition, STAT3 serves a vital role in the process of autophagy (19). For example, Guo et al (20) reported that repression of STAT3 via its inhibitor, isocryptotanshinone enhances autophagy in the A549 lung cancer cell line.

The present study aimed to investigate the effects of $\mathrm{H}_{2}$ on autophagy and apoptosis in lung cancer cells, and the role of STAT3 in this process. The results demonstrated that $\mathrm{H}_{2}$ could promote lung cancer cell apoptosis and autophagy by inhibiting the activation of the STAT3/Bcl2 signaling pathway and suppression of autophagy could enhance $\mathrm{H}_{2}$ roles in promoting lung cancer cell apoptosis.

\section{Materials and methods}

Cell lines and culture. The human A549 and H1975 lung cancer cell lines, were purchased from American Type Culture Collection. The A549 cell line was cultured in F-12K medium, supplemented with $10 \%$ fetal bovine serum (FBS), while the H1975 cell line was cultured in RPMI-1640 medium containing 10\% FBS (all from Gibco; Thermo Fisher Scientific, Inc.). The two cell lines were maintained in an incubator at $37^{\circ} \mathrm{C}$ with $5 \% \mathrm{CO}_{2}$.

Cell transfection and treatments. Three short interfering (si)RNAs used to silence Beclin1 (si-Beclin1-1/2-3; cat. no. SR322490) in the A549 and H1975 cells, and the negative control vector (si-NC, cat. no. SR322490) were purchased from OriGene Technologies, Inc.. The overexpressing plasmid STAT3 (OE-STAT3, cat. no. SC124165) and OE-NC (cat. no. SC124165) were also obtained from OriGene Technologies, Inc.. Cell transfection was performed using the transfection reagent Lipofectamine ${ }^{\circledR} 2000$ (Invitrogen; Thermo Fisher Scientific, Inc.) according to the manufacturer's protocols with $2 \mu \mathrm{g}$ OE-STAT3/OE-NC or $0.3 \mu \mathrm{g}$ si-Beclin $1 / \mathrm{si}-\mathrm{NC}$ for each well of a 6 -well plate. Following $48 \mathrm{~h}$ of transfection, cells were harvested for analysis. The siRNA sequences were as follow: si-NC, Forward: 5'-UUCUCCGAACGUGUCACG UTT-3' and reverse: 5'-ACGUGACACGUUCGGAGAATT-3'; si-Beclin1-1, forward: 5'-CUGGACACGAGUUUCAAG ATT-3' and reverse: 5'-UCUUGAAACUCGUGUCCAGTT-3'; si-Beclin1-2, forward: 5'-GUGGAAUGGAAUGAGAUU ATT-3' and reverse: 5'-UAAUCUCAUUCCAUUCCACTT-3'; si-Beclin1-3, forward: 5'-GCUGCCGUUAUACUGUUC UTT-3' and reverse: 5'-AGAACAGUAUAACGGCAGCTT-3'.

For $\mathrm{H}_{2}$ treatment, A549 and H1975 cells were cultured in different concentrations of $\mathrm{H}_{2}(20,40$ and $60 \%)$ with the assistance of Shanghai Nanobubble Technology Co., Ltd. (http://www.nanobubble.cn/p-about.html?app=mb) for different time points $(12,24,36,48$ or $72 \mathrm{~h})$, and $5 \% \mathrm{CO}_{2}$ served as the negative control.

A549 and H1975 cells were treated with $2 \mathrm{mM}$ 3-methyladenine (3-MA) or $100 \mu \mathrm{M}$ rapamycin (RAPA) for $48 \mathrm{~h}$ to repress and induce autophagy, respectively.

Western blot analysis. Total protein was extracted from the cells using the RIPA lysis buffer (Sangon Biotech Co., Ltd.), containing protease inhibitor (Beyotime Institute of Biotechnology) and according to the manufacturer's instructions. After quantification with a bicinchoninic acid protein kit (Bio-Rad Laboratories, Inc.), $30 \mu \mathrm{g}$ protein from each sample was loaded per lane and separated using $10 \%$ SDS-PAGE. Then, the proteins were transferred onto polyvinylidene difluoride membranes (EMD Millipore), and blocked with 5\% skimmed milk at room temperature for $1 \mathrm{~h}$, following which the membranes were incubated with the following primary antibodies, overnight at $4^{\circ} \mathrm{C}$ : Cleaved-caspase 3 (1:1,000 dilution; cat. no. ab2302; Abcam), cleaved poly ADP-ribose polymerase (PARP; 1:1,000 dilution; cat. no. ab32064; Abcam), Beclin1 (1:2,000 dilution; cat. no. ab207612; Abcam), p62 (1:1,000 dilution; cat. no. ab56416; Abcam), LC3B (1:3,000 dilution; cat. no. ab51520; Abcam), Bcl2 (1:1,000 dilution; cat. no. 15071; Cell Signaling Technology, Inc.), STAT3 (1:1,000 dilution; cat. no. 9139; Cell Signaling Technology, Inc.), phosphorylated (p)-STAT3 (1:1,000 dilution; cat. no. 9145; Cell Signaling Technology, Inc.) and $\beta$-actin (1:4,000 dilution; cat. no. 3700; Cell Signaling Technology, Inc.). After the incubation with the corresponding secondary antibodies (Santa Cruz Biotechnology, Inc.), the protein expression levels were detected using a western blot imaging and quantitative system (Bio-Rad Laboratories, Inc.). Protein quantification was performed using the ImageJ software (version 1.48; National Institutes of Health) after background subtraction, with $\beta$-actin as an internal reference.

Cell counting Kit-8 assay (CCK-8). A CCK-8 assay was used to determine cell proliferation ability according to the manufacturer's instructions. In brief, A549 and H1975 cells were cultured in 96-well plates at a density of $2 \times 10^{3}$ cells/well, overnight at $37^{\circ} \mathrm{C}$. Then, the cells were treated with different concentrations of $\mathrm{H}_{2}$ for $12,24,36,48$ or $72 \mathrm{~h}$. Following which, the cell culture medium was replaced with $10 \mu \mathrm{l} \mathrm{CCK}-8$ reagent (Beyotime Institute of Biotechnology) and $90 \mu \mathrm{l}$ fresh medium, and incubated at $37^{\circ} \mathrm{C}$ for another $4 \mathrm{~h}$. The absorbance at $450 \mathrm{~nm}$ was determined using a plate reader (model 680; Bio-Rad Laboratories, Inc.).

Flow cytometry assay. Cell apoptosis was determined using flow cytometry and an Annexin V-FITC/propidium iodide (PI) kit (Thermo Fisher Scientific, Inc.) in accordance with the manufacturer's protocols. Briefly, A549 and H1975 cells were harvested through centrifugation at $110 \mathrm{x} g$ for 5 min at $4^{\circ} \mathrm{C}$ and washed once with PBS following $48 \mathrm{~h}$ of $\mathrm{H}_{2}$ treatment and/or cell transfection. Then, the cells were incubated with Annexin V-FITC and PI solution for $15 \mathrm{~min}$ in the dark, at room temperature. The fluorescent signals were evaluated using flow cytometry (BD Biosciences) within $1 \mathrm{~h}$ of staining using Flowjo version 7.6 software (FlowJo LLC). Cells in the FITC/PI' quadrant represented live cells, while 
A
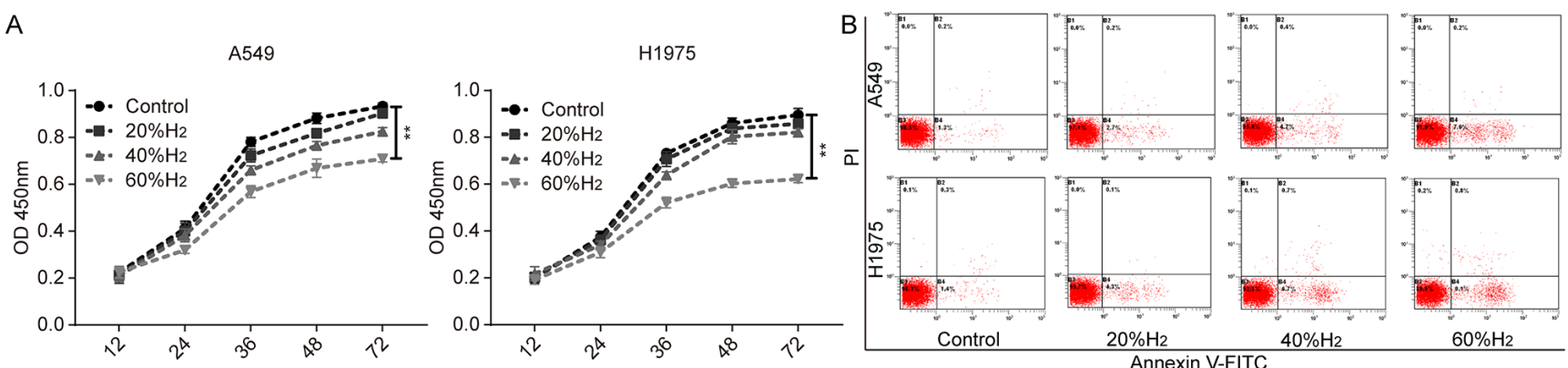

C

\section{D}

A549
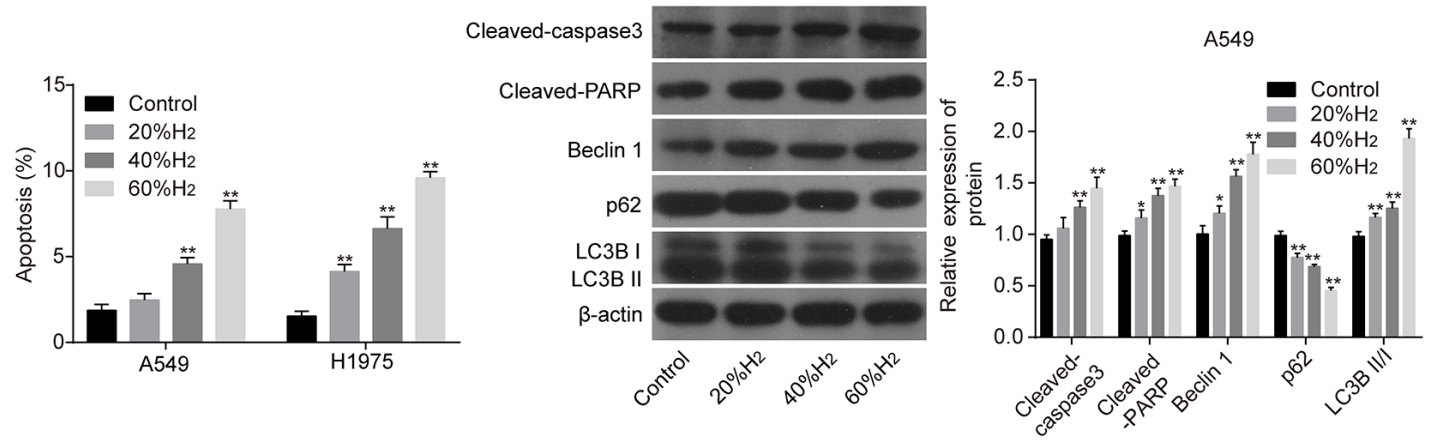

$\mathrm{E}$
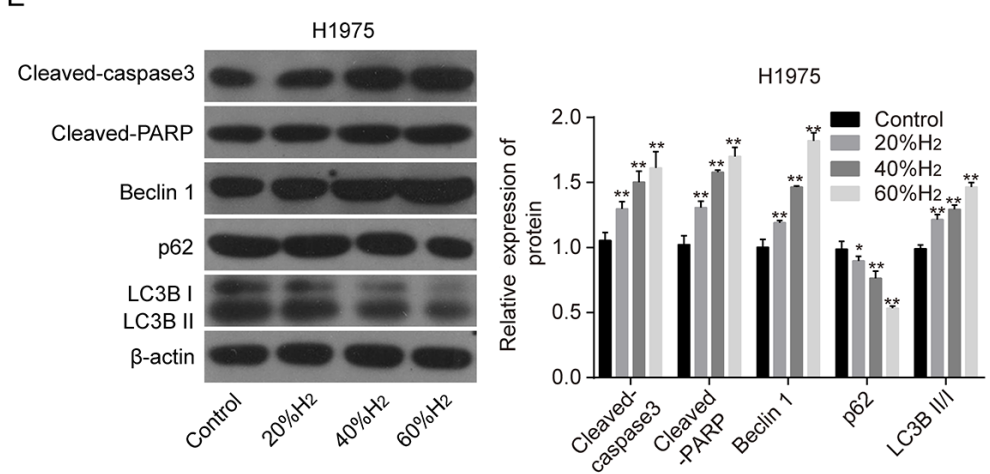

Figure $1 . \mathrm{H}_{2}$ treatment enhances lung cancer cell apoptosis and autophagy. After A549 and $\mathrm{H} 1975$ cells were treated with 20,40 or $60 \% \mathrm{H}_{2}$, the following assays were performed. (A) Cell Counting Kit-8 assay was used to investigate cell growth. (B and C) Flow cytometry assay was used to detect cell apoptosis. (D and E) The protein levels of cleaved-caspase 3, cleaved-PARP, p62, Beclin1, LC3BII and LC3BI were detected using western blot analysis. "P<0.05 and ${ }^{* *} \mathrm{P}<0.01$ vs. control. PARP, poly ADP-ribose polymerase; LC3, light chain $3 ; \mathrm{H}_{2}$, hydrogen gas.

FITC $^{+} / \mathrm{PI}^{-}$represented early apoptotic cells and $\mathrm{FITC}^{+} / \mathrm{PI}^{+}$ represented late apoptotic cells.

Statistical analysis. Each experiment was performed in triplicate. Data are presented the mean \pm standard deviation. Statistically significant comparisons between two groups and multiple groups were performed using unpaired Student's t-test and one-way ANOVA, followed by Dunnett's or Tukey's post hoc test. Data analysis was performed using the SPSS software (version 23.0, IBM Corp.). $\mathrm{P}<0.05$ was considered to indicate a statistically significant difference.

\section{Results}

$\mathrm{H}_{2}$ treatment induces significant increases in cell apoptosis and autophagy. The present study first investigated the effects of $\mathrm{H}_{2}$ treatment on the apoptosis and autophagy of lung cancer cells. Compared with that in the control group, cell viability was reduced following treatment with $\mathrm{H}_{2}$, in a time-dependent manner, in both A549 and H1975 cells (Fig. 1A), along with increased apoptosis rates (Fig. 1B and C). The expression levels of pro-apoptotic proteins, including cleaved-caspase 3 and cleaved-PARP were significantly increased followed $\mathrm{H}_{2}$ treatment compared with that in the control group (Fig. 1D and E), in a dose-dependent manner, in both cell lines. In addition, Beclin1 expression and the ratio of LC3BII/I were also significantly increased following $\mathrm{H}_{2}$ treatment, while the expression of p62 was significantly reduced (Fig. 1D and E), also in a dose-dependent manner. These findings demonstrated that $\mathrm{H}_{2}$ could induce cell apoptosis and autophagy in lung cancer cell lines.

Autophagy weakens the role of $\mathrm{H}_{2}$ in promoting cell apoptosis in lung cancer cells. The autophagy roles in $\mathrm{H}_{2}$-induced cell apoptosis in lung cancer cells were subsequently investigated. The protein expression levels of Beclin1 and LC3BII/I were significantly increased, while that of p62 was reduced when A549 and H1975 cells were treated with RAPA, an autophagy inducer (Fig. 2A). As $60 \% \mathrm{H}_{2}$ resulted in significant changes in cell viability and apoptosis, $60 \% \mathrm{H}_{2}$ was selected for the subsequent 

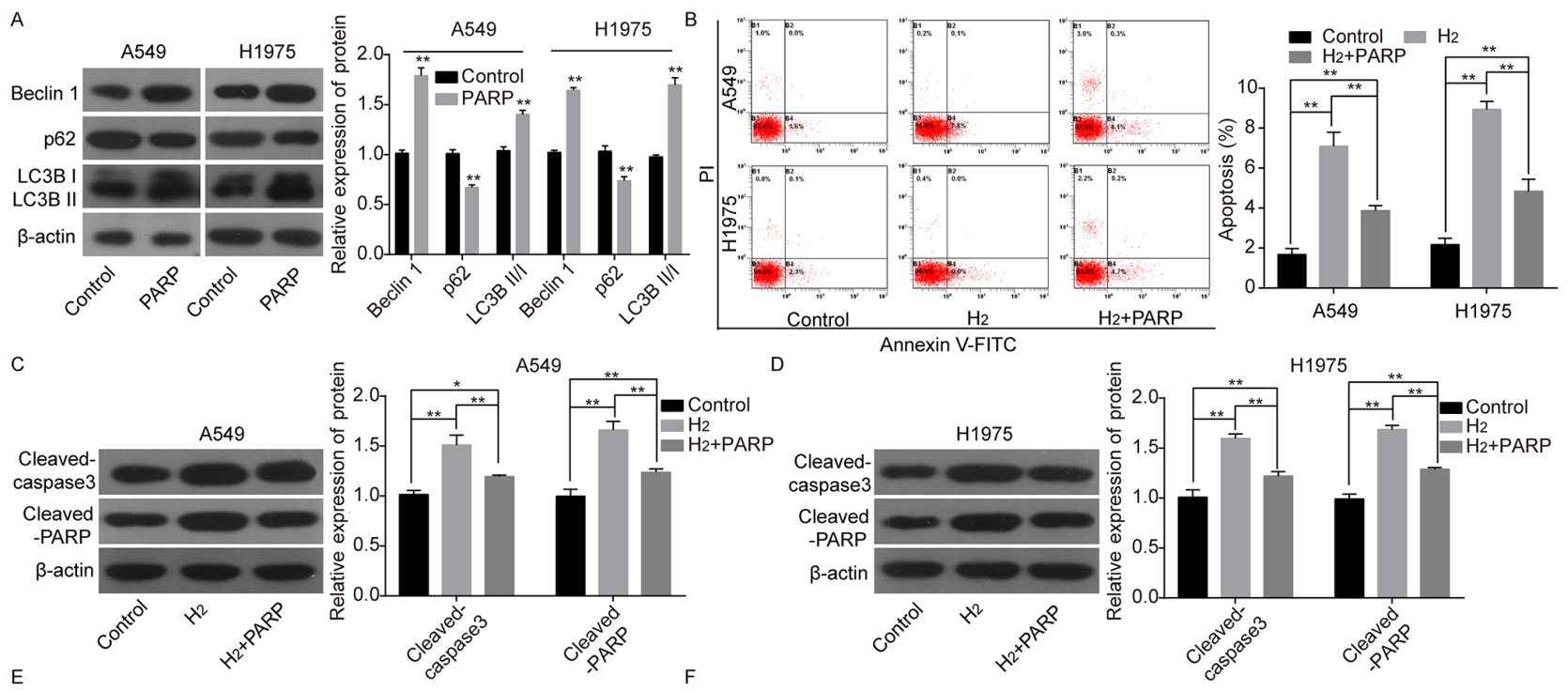

D
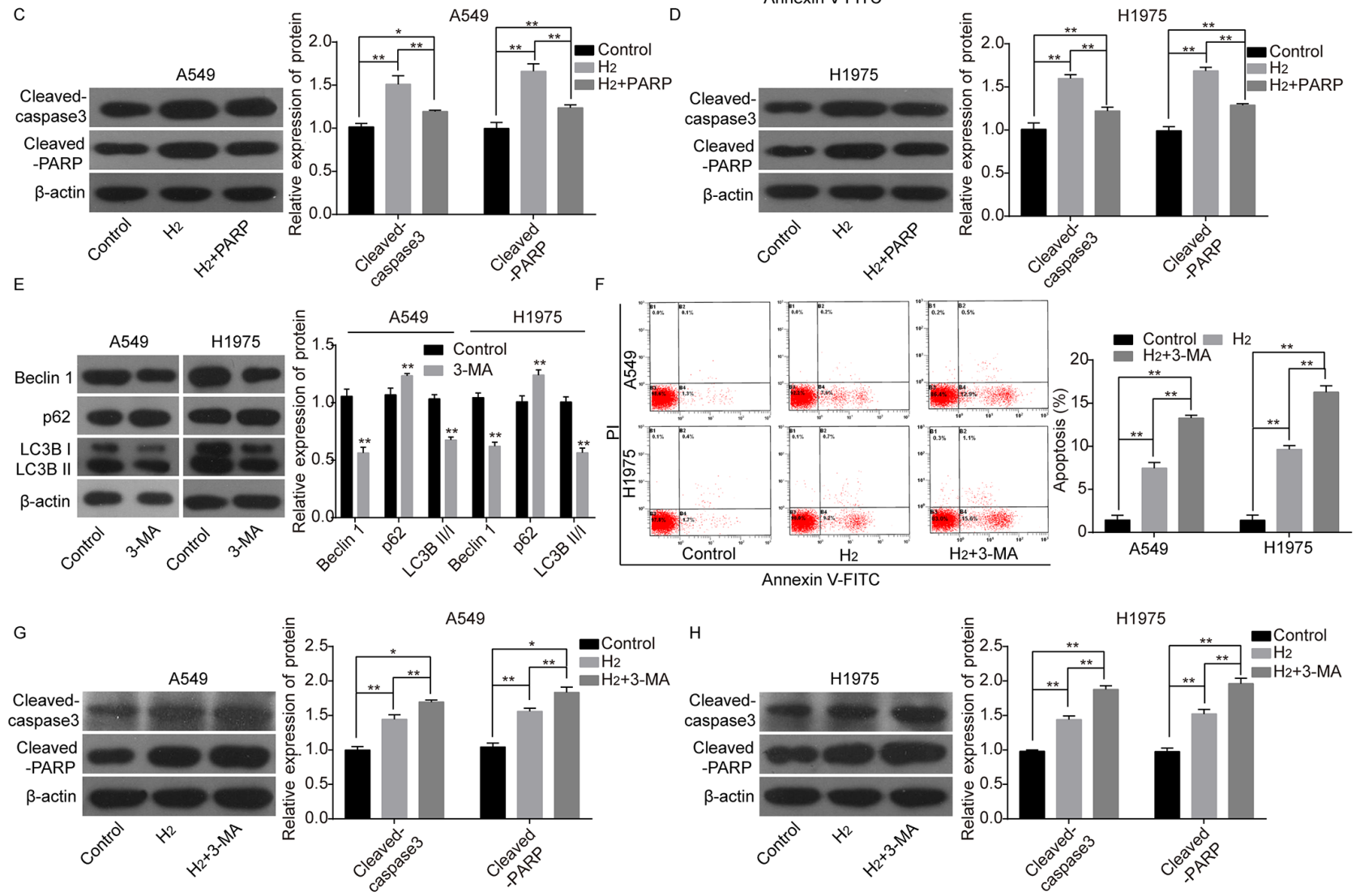

Figure 2. Evaluation of autophagy effects on $\mathrm{H}_{2}$-induced lung cancer cell apoptosis. (A) The protein expression levels of p62, Beclin1, LC3BII and LC3BI, following treatment of A549 and H1975 cells with RAPA were detected using western blot analysis. (B) Cell apoptosis was investigated using a flow cytometry assay. Western blot analysis of the expression of cleaved-caspase 3 and cleaved-PARP in (C) A549 and (D) $\mathrm{H} 1975$ cells treated with $\mathrm{H}_{2}$ or $\mathrm{H}_{2}+\mathrm{RAPA}$. (E) The protein expression levels of p62, Beclin1, LC3BII and LC3BI were detected using western blot analysis following treatment of A549 and H1975 cells with 3-MA. (F) Cell apoptosis was investigated using flow cytometry. Western blot analysis of the protein expression levels of cleaved-caspase 3 and cleaved-PARP following treatment of (G) A549 and (H) $\mathrm{H} 1975$ cells with $\mathrm{H}_{2}$ or $\mathrm{H}_{2}+3$-MA. ${ }^{*} \mathrm{P}<0.05 .{ }^{* *} \mathrm{P}<0.01$. LC3, light chain 3; RAPA, rapamycin; PARP, poly ADP-ribose polymerase; PI, propidium iodide; 3-MA, 3-methyladenine; $\mathrm{H}_{2}$, hydrogen gas.

experiments. Following RAPA treatment, cell apoptosis rates (Fig. 2B) and the protein expression levels of cleaved-caspase 3 and cleaved-PARP (Fig. 2C and D) were significantly decreased compared with that in the $\mathrm{H}_{2}$ group. By contrast, the protein expression levels of Beclin1 and LC3BII/I were significantly decreased and p62 expression was increased following cell treatment with 3-MA, an autophagy repressor (Fig. 2E). In addition, 3-MA treatment enhanced $\mathrm{H}_{2}$-mediated increases in cell apoptosis rates (Fig. 2F) and the protein expression levels of cleaved-caspase 3 and cleaved-PARP as compared with the $\mathrm{H}_{2}$ group (Fig. 2G and $\mathrm{H}$ ). These results revealed that autophagy weakened $\mathrm{H}_{2}$ roles in inducing cell apoptosis in lung cancer cells.

Knockdown of Beclinl enhances the roles of $\mathrm{H}_{2}$ in promoting cell apoptosis in lung cancer cell lines. To further clarify the role of autophagy in $\mathrm{H}_{2}$-mediated lung cancer cell apoptosis, knockdown experiments were performed. The expression of Beclin1 was significantly decreased in A549 and H1975 cells transfected with the siRNAs targeting the human Beclin1 gene. As si-Beclin1-3 significantly reduced the protein expression level of Beclin1 among the 3 siRNAs (Fig. 3A), this was chosen for the subsequent experiments. Following cell transfection with si-Beclin1-3, the protein expression level of p62 was increased and the expression ratio of LC3BII:LC3BI was decreased (Fig. 3B and C). Notably, cell apoptosis induced by $\mathrm{H}_{2}$ treatment was significantly increased when Beclin1 was silenced in both A549 and H1975 cells as compared with the $\mathrm{H}_{2}$ group (Fig. 3D). In addition, knockdown of Beclin1 increased the protein expression levels of cleaved-caspase 3 and cleaved-PARP in A549 and $\mathrm{H} 1975$ cells following $\mathrm{H}_{2}$ treatment compared with cells treated with $\mathrm{H}_{2}$ only (Fig. 3E and $\mathrm{F}$ ). These findings further confirmed that autophagy inhibition 
A

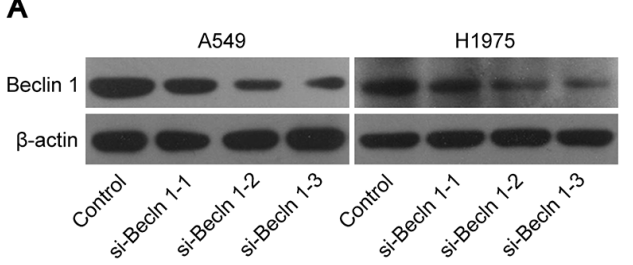

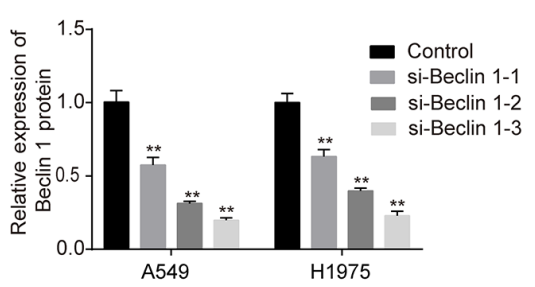

D
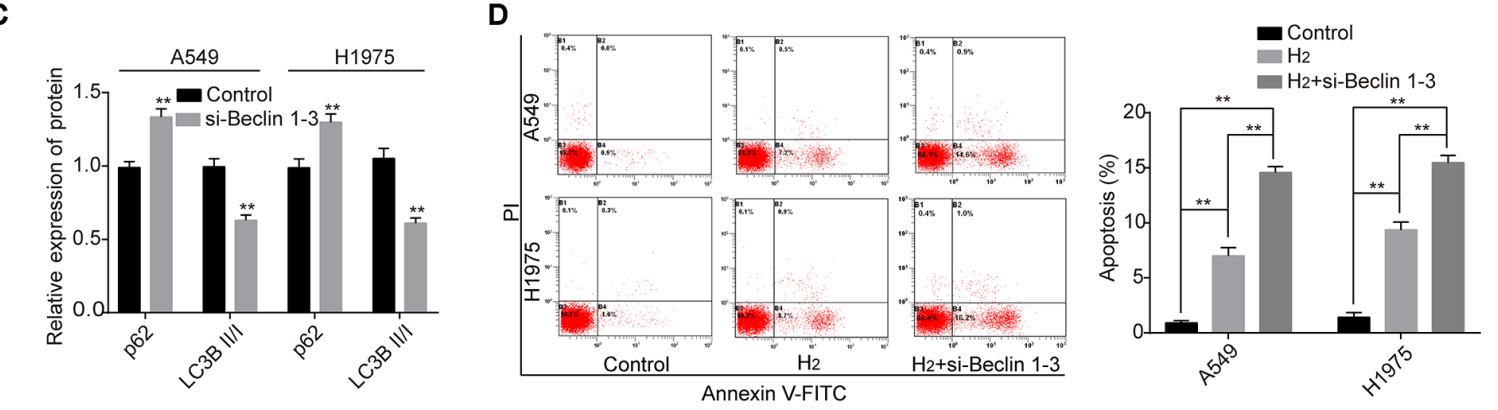

E
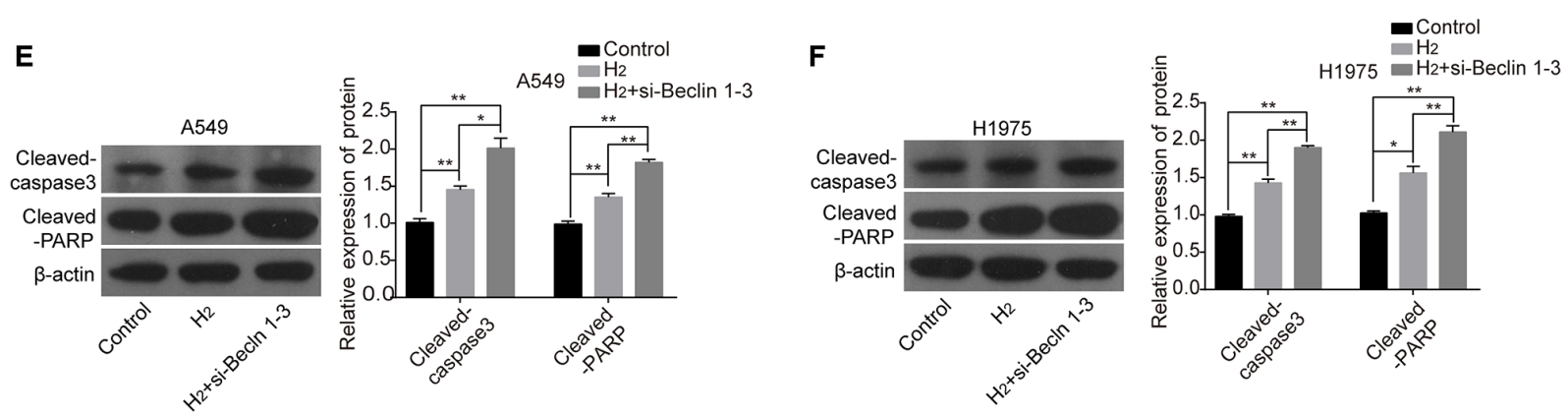

B

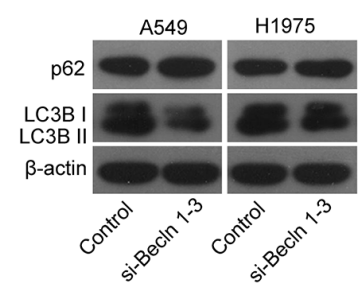$$
\text { . }
$$

Figure 3. Knockdown of Beclin1 enhances the role of $\mathrm{H}_{2}$ in promoting lung cancer cell apoptosis. (A) The knockdown efficiency of si-Beclin1 in A549 and H1975 cells was detected using western blot analysis. (B) Western blot analysis was used to detect the protein expression levels of p62, LC3BII and LC3BI in A549 and H1975 cells and the results were subsequently (C) quantified. (D) Flow cytometry assay was used to investigate cell apoptosis. The protein expression levels of cleaved-caspase 3 and cleaved-PARP were determined using western blot analysis in (E) A549 and (F) H1975 cells. ${ }^{*} \mathrm{P}<0.05$ and ${ }^{* * *} \mathrm{P}<0.01$. si, short interfering; LC3, light chain 3; PARP, poly ADP-ribose polymerase; PI, propidium iodide; $\mathrm{H}_{2}$, hydrogen gas.

could enhance the effects of $\mathrm{H}_{2}$ on inducing cell apoptosis in lung cancer cell lines.

$\mathrm{H}_{2}$ treatment induces lung cancer cell apoptosis and autophagy by repressing the STAT3/Bcl2 signaling pathway. Next, the roles of the STAT3/Bcl 2 signaling pathway in $\mathrm{H}_{2}$-mediated cell apoptosis and autophagy in lung cancer cell lines were investigated. The protein expression levels of p-STAT3 and $\mathrm{Bcl} 2$ were significantly decreased following $\mathrm{H}_{2}$ treatment in $\mathrm{H} 1975$ and A549 cells in a dose-dependent manner (Fig. 4A and B), whereas STAT3-overexpression abolished this effect (Fig. 4C-E). In addition, overexpression of STAT3 in $\mathrm{H}_{2}$-treated cells inhibited lung cancer cell apoptosis and neutralized $\mathrm{H}_{2}$-mediated increases in apoptosis (Fig. 4F and G), along with the decreased protein expression levels of cleaved-caspase 3 , cleaved-PARP, Beclin1, LC3BII/I and the increased expression of p62 (all vs. $\mathrm{H}_{2}$ group; Fig. $4 \mathrm{H}$ and I). The aforementioned findings suggested that $\mathrm{H}_{2}$ treatment promoted lung cancer cell apoptosis and autophagy by repressing the activation of the STAT3/Bcl2 signaling pathway.

\section{Discussion}

As a colorless, odorless, tasteless, non-toxic and highly combustible gas, $\mathrm{H}_{2}$ exerts multiple roles, including anti-reactive 

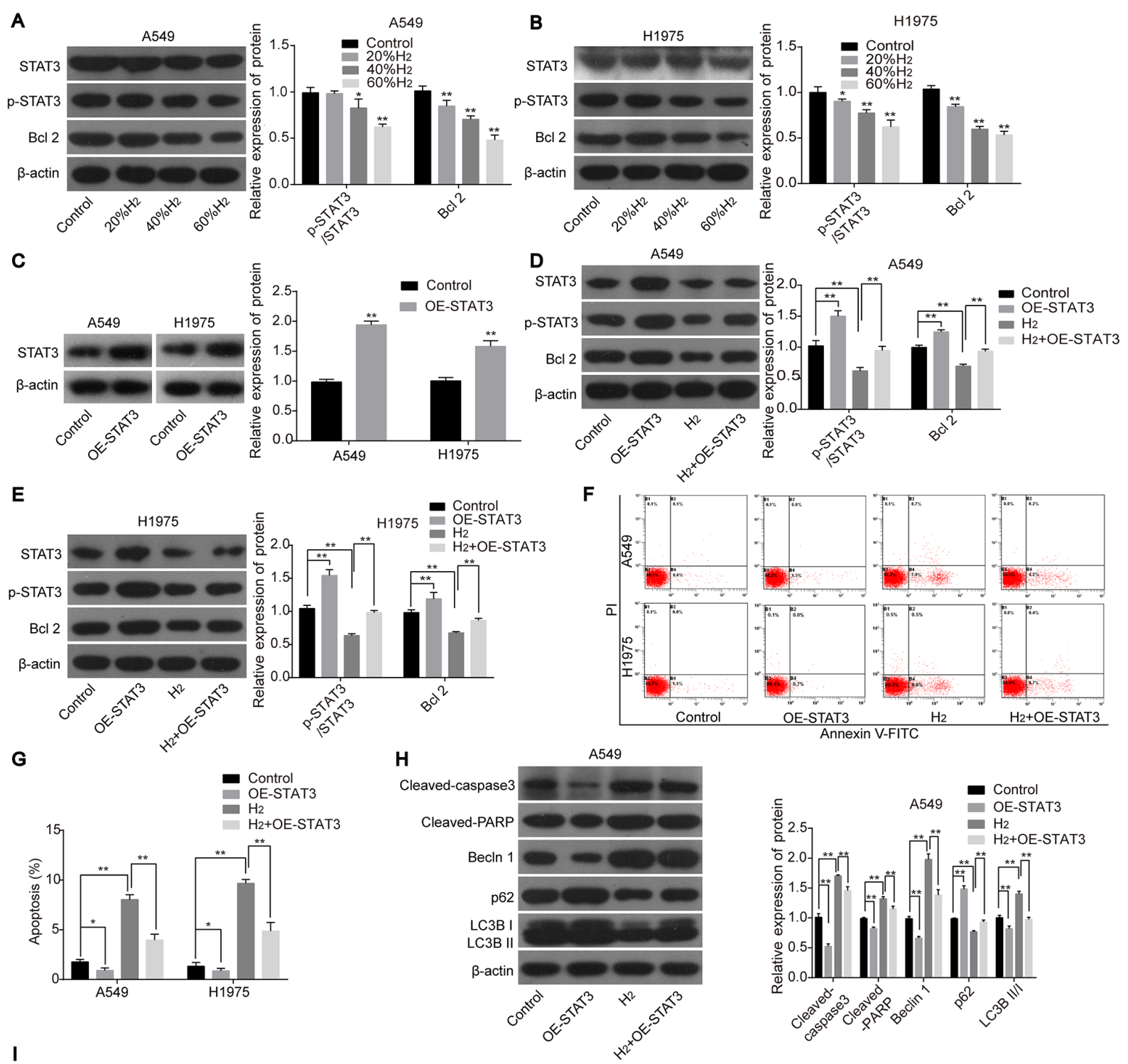

I

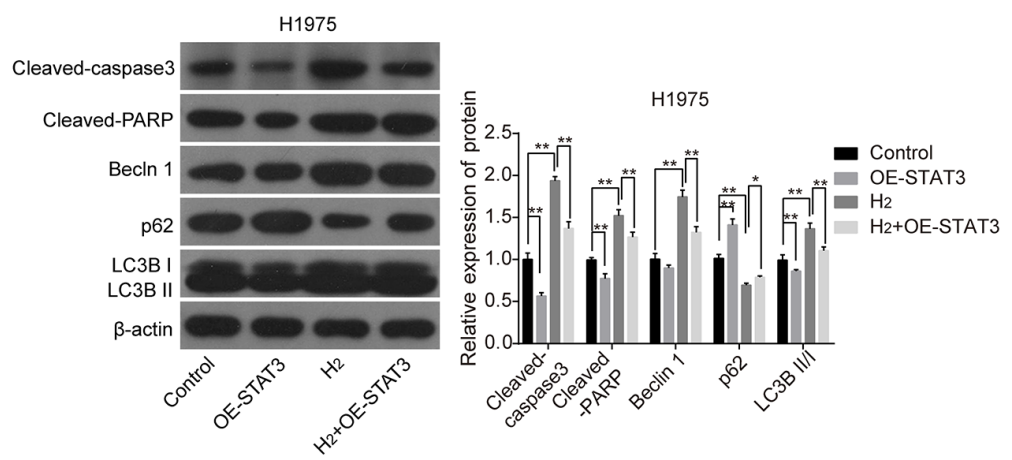

Figure $4 . \mathrm{H}_{2}$ treatment increases lung cancer cell apoptosis and autophagy by repressing the activation of the STAT3/Bcl2 signaling pathway. The protein expression levels of STAT3, p-STAT3 and Bcl2 were detected using western blot analysis in (A) A549 and (B) H1975 cells following treatment with different concentrations of $\mathrm{H}_{2}$. (C) STAT3 expression was detected using western blot analysis following transfection with OE-STAT3 or OE-NC. The protein expression levels of STAT3, p-STAT3 and Bcl2 were detected using western blot analysis in (D) A549 and (E) H1975 cells following treatment with $\mathrm{H}_{2}$ and/or transfected with OE-STAT3. Cell apoptosis was investigated using (F) flow cytometry and the results were subsequently (G) quantified. The protein expression levels of cleaved-caspase 3, cleaved-PARP, Beclin1, p62, LC3BII and LC3BI in (H) A549 and (I) H1975 cells were detected using western blot analysis following transfection with OE-STAT3 and/or treated with $\mathrm{H}_{2} .{ }^{*} \mathrm{P}<0.05$ and ${ }^{* *} \mathrm{P}<0.01$. STAT, signal transducer and activator of transcription; p-, phosphorylated; PARP, poly ADP-ribose polymerase; LC3, light chain $3 ; \mathrm{H}_{2}$, hydrogen gas; OE, overexpression; NC, negative control

in carcinogenesis (31). In lung cancer, inhibition of autophagy enhances the anti-angiogenic property of anlotinib (32), suggesting an angiogenic role of autophagy in lung cancer. Yin et al (33) reported that inhibition of autophagy induced by mucolipin-1 (which is a member of the transient receptor potential cation channel family) downregulation repressed the progression of lung cancer. Li et al (34), demonstrated that autophagy enhancement caused by apurinic endonuclease 1 
significantly increased the resistance of lung cancer cells to cisplatin. These findings suggested that autophagy may exert an oncogenic role in lung cancer progression. By contrast, Fan et al (35) reported that Bruceine D, a quassinoid compound, which can be extracted from the seeds of Brucea javanica, inhibits lung cancer progression by inducing cell apoptosis and autophagy, suggesting a suppressive role of autophagy in lung cancer progression. These findings indicate that autophagy serves an important role in lung cancer progression, therefore autophagy plays a role in $\mathrm{H}_{2}$-induced cell apoptosis in lung cancer cell lines.

When autophagy is induced, Beclin1 and LC3 are distributed to the autophagosome membrane to trigger the formation of autophagosome, whereas p62 expression is decreased $(36,37)$. The transformation of LC3I to LC3BII is the most common autophagosome marker, as the amount of LC3BII reflects the number of autophagosomes and autophagy-related structures (38). The present study found that $\mathrm{H}_{2}$ treatment significantly increased the protein expression level of Beclin1, and the conversion of LC3BI to LC3BII, and decreased the expression level of p62, indicating that $\mathrm{H}_{2}$ treatment could trigger lung cancer cell autophagy. Several studies have investigated the role of $\mathrm{H}_{2}$ treatment in autophagy. In detail, Guan et al (39) reported that $\mathrm{H}_{2}$ treatment induced autophagy and protected Sprague-Dawley rats against chronic intermittent hypoxia-induced renal dysfunction. In addition, inhaling $2 \% \mathrm{H}_{2}$ resulted in an increase in the expression of LC3BII and attenuated sepsis-induced liver injury (40). However, in a myocardial ischemia reperfusion model of rats, $\mathrm{H}_{2}$ inhalation significantly reduced the ischemic size and serum troponin I level by repressing autophagy (41). The effects might be tissue specific.

In addition, the present study also investigated the role of autophagy in $\mathrm{H}_{2}$-mediated cell apoptosis. The results demonstrated that autophagy enhancement by RAPA stimulation significantly weakened $\mathrm{H}_{2}$-mediated cell apoptosis in both A549 and H1975 lung cancer cell lines, whereas autophagy inhibition by 3-MA treatment or siRNA-Beclin1 transfection significantly enhanced the roles of $\mathrm{H}_{2}$ in promoting lung cancer cell apoptosis, indicating that autophagy inhibition could enhance the antitumor role of $\mathrm{H}_{2}$ in lung cancer.

As the STAT3/Bcl2 signaling pathway serves an important role in cell autophagy and apoptosis $(42,43)$, the present study also investigated the effects of the STAT3/Bcl2 signaling pathway on $\mathrm{H}_{2}$-mediated lung cancer cell autophagy and apoptosis. It was found that the phosphorylation protein expression levels of STAT3 and $\mathrm{Bcl} 2$ were significantly inhibited when A549 and $\mathrm{H} 1975$ cells were treated with $\mathrm{H}_{2}$, suggesting that $\mathrm{H}_{2}$ could repress the activation of the STAT3/Bcl2 signaling pathway. Consistent with this result, Bai et al (44) found that hydrogen-rich saline treatment increased LC3B and Beclin1 protein expression levels and decreased the protein phosphorylation level of STAT3 in hypoxic-ischemic brain damaged mice. To further investigate the roles of STAT3/Bcl2 in $\mathrm{H}_{2}$-mediated cell apoptosis and autophagy in lung cancer, rescue experiments were also performed in the present study. The results demonstrated that overexpression of STAT3 neutralized the $\mathrm{H}_{2}$ roles in increasing cell autophagy and apoptosis, suggesting that $\mathrm{H}_{2}$ induced lung cancer apoptosis and autophagy by inhibiting the STAT3/Bcl2 signaling pathway.
In summary, the present study revealed that $\mathrm{H}_{2}$ could promote lung cancer cell apoptosis and autophagy by inhibiting the STAT3/Bcl2 signaling pathway and that suppression of autophagy could enhance the roles of $\mathrm{H}_{2}$ in promoting lung cancer cell apoptosis. The current study might provide a novel application of $\mathrm{H}_{2}$ in the treatment of lung cancer.

\section{Acknowledgements}

Not applicable.

\section{Funding}

The present study was funded by the Excellent Personnel Training Program (Studying of the Molecular Mechanism and Clinical Transformation of Hydrogen in the Treatment of Lung Cancer; grant no. zh2018006).

\section{Availability of data and materials}

All data generated or analyzed during this study are included in this published article.

\section{Authors' contributions}

GC conceived and designed the project. LL performed the majority of the experiments and wrote the paper. ZY analyzed the data. YW and JM performed parts of the experiments. All authors approved the final version of the manuscript.

\section{Ethics approval and consent to participate}

Not applicable.

\section{Patient consent for publication}

Not applicable.

\section{Competing interests}

The authors declare that they have no competing interests.

\section{References}

1. Zhao P, Jin Z, Chen Q, Yang T, Chen D, Meng J, Lu X, Gu Z and He Q: Local generation of hydrogen for enhanced photothermal therapy. Nat Commun 9: 4241, 2018.

2. Ohsawa I, Ishikawa M, Takahashi K, Watanabe M, Nishimaki K, Yamagata K, Katsura K, Katayama Y, Asoh S and Ohta S: Hydrogen acts as a therapeutic antioxidant by selectively reducing cytotoxic oxygen radicals. Nat Med 13: 688-694, 2007.

3. Ono H, Nishijima Y, Adachi N, Sakamoto M, Kudo Y, Nakazawa J, Kaneko K and Nakao A: Hydrogen(H2) treatment for acute erythymatous skin diseases. A report of 4 patients with safety data and a non-controlled feasibility study with $\mathrm{H} 2$ concentration measurement on two volunteers. Med Gas Res 2: 14, 2012.

4. Chen J, Kong X, Mu F, Lu T, Du D and Xu K: Hydrogen-oxygen therapy can alleviate radiotherapy-induced hearing loss in patients with nasopharyngeal cancer. Ann Palliat Med 8: 746-751, 2019.

5. Dole M, Wilson FR and Fife WP: Hyperbaric hydrogen therapy: A possible treatment for cancer. Science 190: 152-154, 1975.

6. Wang D, Wang L, Zhang Y, Zhao Y and Chen G: Hydrogen gas inhibits lung cancer progression through targeting SMC3. Biomed Pharmacother 104: 788-797, 2018. 
7. Gordy $\mathrm{C}$ and $\mathrm{He} \mathrm{YW}$ : The crosstalk between autophagy and apoptosis: Where does this lead? Protein Cell 3: 17-27, 2012.

8. Levine B and Kroemer G: Autophagy in the pathogenesis of disease. Cell 132: 27-42, 2008

9. Sotthibundhu A, McDonagh K, von Kriegsheim A, Garcia-Munoz A, Klawiter A, Thompson K, Chauhan KD, Krawczyk J, McInerney V, Dockery P, et al: Rapamycin regulates autophagy and cell adhesion in induced pluripotent stem cells. Stem Cell Res Ther 7: 166, 2016.

10. Boya P, Reggiori $F$ and Codogno P: Emerging regulation and functions of autophagy. Nat Cell Biol 15: 713-720, 2013.

11. Levine B: Cell biology: Autophagy and cancer. Nature 446: 745-747, 2007.

12. Galluzzi L, Pietrocola F, Bravo-San Pedro JM, Amaravadi RK, Baehrecke EH, Cecconi F, Codogno P, Debnath J, Gewirtz DA, Karantza V, et al: Autophagy in malignant transformation and cancer progression. EMBO J 34: 856-880, 2015.

13. Wasik AM, Grabarek J,Pantovic A, Cieślar-Pobuda A, Asgari HR, Bundgaard-Nielsen C, Rafat M, Dixon IM, Ghavami S and Łos MJ: Reprogramming and carcinogenesis-parallels and distinctions. Int Rev Cell Mol Biol 308: 167-203, 2014.

14. Sridhar S, Botbol Y, Macian F and Cuervo AM: Autophagy and disease: Always two sides to a problem. J Pathol 226: 255-273, 2012.

15. Levy DE and Darnell JE Jr: Stats: Transcriptional control and biological impact. Nat Rev Mol Cell Biol 3: 651-662, 2002.

16. Akira S, Nishio Y, Inoue M, Wang XJ, Wei S, Matsusaka T, Yoshida K, Sudo T, Naruto M and Kishimoto T: Molecular cloning of APRF, a novel IFN-stimulated gene factor 3 p91-related transcription factor involved in the gp130-mediated signaling pathway. Cell 77: 63-71, 1994.

17. Niu G, Wright KL, Huang M, Song L, Haura E, Turkson J, Zhang S, Wang T, Sinibaldi D, Coppola D, et al: Constitutive Stat 3 activity up-regulates VEGF expression and tumor angiogenesis. Oncogene 21: 2000-2008, 2002.

18. Tong M, Wang J, Jiang N, Pan H and Li D: Correlation between p-STAT3 overexpression and prognosis in lung cancer: A systematic review and meta-analysis. PLoS One 12: e0182282, 2017.

19. You L, Wang Z, Li H, Shou J, Jing Z, Xie J, Sui X, Pan H and Han W: The role of STAT3 in autophagy. Autophagy 11: 729-739, 2015.

20. Guo S, Luo W, Liu L, Pang X, Zhu H, Liu A, Lu J, Ma DL, Leung $\mathrm{CH}$, Wang $\mathrm{Y}$ and Chen X: Isocryptotanshinone, a STAT3 inhibitor, induces apoptosis and pro-death autophagy in A549 lung cancer cells. J Drug Target 24: 934-942, 2016.

21. Li S, Liao R, Sheng X, Luo X, Zhang X, Wen X, Zhou J and Peng K: Hydrogen gas in cancer treatment. Front Oncol 9: 696, 2019.

22. Li FY, Zhu SX, Wang ZP, Wang H, Zhao Y and Chen GP: Consumption of hydrogen-rich water protects against ferric nitrilotriacetate-induced nephrotoxicity and early tumor promotional events in rats. Food Chem Toxicol 61: 248-254, 2013.

23. Zhou P, Lin B, Wang P, Pan T, Wang S, Chen W, Cheng S and Liu S: The healing effect of hydrogen-rich water on acute radiationinduced skin injury in rats. J Radiat Res 60: 17-22, 2019.

24. Wu Y, Yuan M, Song J, Chen X and Yang H: Hydrogen gas from inflammation treatment to cancer therapy. ACS Nano 13 $8505-8511,2019$.

25. Chen JB, Pan ZB, Du DM, Qian W, Ma YY, Mu F and Xu KC: Hydrogen gas therapy induced shrinkage of metastatic gallbladder cancer: A case report. World J Clin Cases 7: 2065-2074, 2019.

26. Liu G, Pei F, Yang F, Li L, Amin AD, Liu S, Buchan JR and Cho WC: Role of autophagy and apoptosis in non-small-cell lung cancer. Int J Mol Sci 18: 367, 2017.

27. Kroemer G, Mariño G and Levine B: Autophagy and the integrated stress response. Mol Cell 40: 280-293, 2010.

28. Dang S, Yu ZM, Zhang CY, Zheng J, Li KL, Wu Y, Qian LL, Yang ZY, Li XR, Zhang Y and Wang RX: Autophagy promotes apoptosis of mesenchymal stem cells under inflammatory microenvironment. Stem Cell Res Ther 6: 247, 2015.
29. Zhang M, Su L, Xiao Z, Liu X, and Liu X: Methyl jasmonate induces apoptosis and pro-apoptotic autophagy via the ROS pathway in human non-small cell lung cancer. Am J Cancer Res 6: 187-199, 2016.

30. Galluzzi L, Bravo-San Pedro JM, Vitale I, Aaronson SA, Abrams JM, Adam D, Alnemri ES, Altucci L, Andrews D, Anni cchiarico-Petruzzelli M, et al: Essential versus accessory aspects of cell death: Recommendations of the NCCD 2015. Cell Death Differ 22: 58-73, 2015.

31. White E: The role for autophagy in cancer. J Clin Invest 125 : 42-46, 2015.

32. Liang L, Hui K, Hu C, Wen Y, Yang S, Zhu P, Wang L, Xia Y, Qiao Y, Sun W, et al: Autophagy inhibition potentiates the anti-angiogenic property of multikinase inhibitor anlotinib through JAK2/STAT3/VEGFA signaling in non-small cell lung cancer cells. J Exp Clin Cancer Res 38: 71, 2019.

33. Yin C, Zhang H, Liu X, Zhang H, Zhang Y, Bai X, Wang L, Li H, Li X, Zhang S, et al: Downregulated MCOLN1 attenuates the progression of non-small-cell lung cancer by inhibiting lysosome-autophagy. Cancer Manag Res 11: 8607-8617, 2019.

34. Li Z, Wang Y, Wu L, Dong Y, Zhang J, Chen F, Xie W, Huang J and $\mathrm{Lu} \mathrm{N}$ : Apurinic endonuclease 1 promotes the cisplatin resistance of lung cancer cells by inducing Parkin-mediated mitophagy. Oncol Rep 42: 2245-2254, 2019.

35. Fan J, Ren D, Wang J, Liu X, Zhang H, Wu M and Yang G: Bruceine D induces lung cancer cell apoptosis and autophagy via the ROS/MAPK signaling pathway in vitro and in vivo. Cell Death Dis 11: 126, 2020.

36. El-Khattouti A, Selimovic D, Haikel Y and Hassan M: Crosstalk between apoptosis and autophagy: Molecular mechanisms and therapeutic strategies in cancer. J Cell Death 6: 37-55, 2013.

37. Thorburn A: Apoptosis and autophagy: Regulatory connections between two supposedly different processes. Apoptosis 13: 1-9, 2008.

38. Gupta NA, Kolachala VL, Jiang R, Abramowsky C, Shenoi A, Kosters A, Pavuluri H, Anania F and Kirk AD: Mitigation of autophagy ameliorates hepatocellular damage following ischemia-reperfusion injury in murine steatotic liver. Am J Physiol Gastrointest Liver Physiol 307: G1088-G1099, 2014.

39. Guan P, Sun ZM, Luo LF, Zhou J, Yang S, Zhao YS, Yu FY, An JR, Wang N and Ji ES: Hydrogen protects against chronic intermittent hypoxia induced renal dysfunction by promoting autophagy and alleviating apoptosis. Life Sci 225: 46-54, 2019.

40. Yan M, Yu Y, Mao X, Feng J, Wang Y, Chen H, Xie K and Yu Y: Hydrogen gas inhalation attenuates sepsis-induced liver injury in a FUNDC1-dependent manner. Int Immunopharmacol 71: 61-67, 2019.

41. Gao Y, Yang H, Chi J, Xu Q, Zhao L, Yang W, Liu W and Yang W: Hydrogen gas attenuates myocardial ischemia reperfusion injury independent of postconditioning in rats by attenuating endoplasmic reticulum stress-induced autophagy. Cell Physiol Biochem 43: 1503-1514, 2017.

42. Liu Y, Gong W, Yang ZY, Zhou XS, Gong C, Zhang TR, Wei X, Ma D, Ye F and Gao QL: Quercetin induces protective autophagy and apoptosis through ER stress via the p-STAT3/Bcl-2 axis in ovarian cancer. Apoptosis 22: 544-557, 2017.

43. Liu K, Ren T, Huang Y, Sun K, Bao X, Wang S, Zheng B and Guo W: Apatinib promotes autophagy and apoptosis through VEGFR2/STAT3/BCL-2 signaling in osteosarcoma. Cell Death Dis 8: e3015, 2017.

44. Bai X, Liu S, Yuan L, Xie Y, Li T, Wang L, Wang X, Zhang T, Qin S, Song G, et al: Hydrogen-rich saline mediates neuroprotection through the regulation of endoplasmic reticulum stress and autophagy under hypoxia-ischemia neonatal brain injury in mice. Brain Res 1646: 410-417, 2016.

This work is licensed under a Creative Commons Attribution-NonCommercial-NoDerivatives 4.0 International (CC BY-NC-ND 4.0) License. 